\title{
Selvmord blant innvandrere i Norge
}

\author{
Av Zhanna Kan, Erik Ganesh I. Søegaard og Suraj B. Thapa
}

MIGRASJONEN MELLOM LAND har eksplodert de senere årene. Okonomiske, politiske og sosiale konflikter sammen med globalisering og okt mobilitet har bidratt til dette. Det var over 244 millioner internasjonale migranter i 2015 (Lee et al., 2015). De største forflyttingene skjer fra lavinntektsland til høyinntektsland. Antall innvandrere i Norge har steget kraftig siden 1970 og var i 2018 17,3 \% av befolkningen. De fleste med innvandrerbakgrunn er bosatt i Oslo. Innad i Oslo varierer andelen med innvandrerbakgrunn også mye, fra under $20 \%$ i de vestlige bydelene til over $55 \%$ i noen østlige- og sørlige bydeler. Tidligere kom innvandrerne til Norge hovedsakelig fra Đst-Afrika, Sør-Asia og VestEuropa, men i de siste par tiårene har det også vært stor arbeidsinnvandring fra øst-europeiske EU-land. Over halvparten av innvandrerne kommer nå fra Europa. Blant norskfødte med innvandrerforeldre har om lag 65 prosent asiatisk eller afrikansk bakgrunn. Til sammen er det personer fra 221 land som bor i Norge (Statistisk sentralbyrå, 2018b).

Migrasion er en heterogen prosess som er unik for hvert individ som flytter til et nytt land. Påkjenninger før, under og etter migrasionen kan øke risikoen for psykiske lidelser og muligens risikoen for selvmord (Norredam et al., 2013). Asylsøkere og flyktninger representerer grupper av innvandrere som er spesielt utsatt for psykiske plager sammenlignet både med arbeidsinnvandrere og befolkningen for øvrig (Lindert et al., 2009). Mange innvandrere beholder en tilknytning til opprinnelseslandet og til familie og venner som fortsatt bor der. Naturkatastrofer, krig og konflikter i hjemlandet kan øke risikoen for psykiske plager hos innvandrere også lenge etter flukt og rebosetting (Guribye, 2011).

Tall fra levekårsundersøkelsen blant innvandrere viste at dobbelt så mange innvandrere rapporterte om psykiske plager sammenliknet med den ovrige befolkningen. Det var stor variasion i landbakgrunn, der personer fra Midtøsten synes spesielt utsatt (Blom, 2010). Flere studier viser at selv om innvandrere har okt prevalens av psykiske plager enn nordmenn, har de generelt sett lavere bruk av både primær- og sekundærhelsetjenesten for sine psykiske plager (Elstad et al., 2015). Stigmatisering av psykiske lidelser i en del kulturer er utbredt, og symptomene kommer for eksempel oftere til uttrykk som somatiske symptomer. Dette kan resultere i underdiagnostisering og underbehandling av psykiske lidelser blant innvandrere sammenlignet med etniske nordmenn. Det kan også være at innvandrere i større grad bruker andre metoder for å håndtere plagene slik som støtte i familien, religiøse og sosiale nettverk, eller at de i større grad klarer å mestre vanskene på egenhånd. Det er kjent at psykiske lidelser øker risikoen for selvmord (Hjorthoj et al., 2014). Imidlertid er suicidal atferd påvirket av svært mange faktorer knyttet til enkeltpersonen og situasjonen. Kultur, religion, familiestruktur og rusbruk er noen risikofaktorer som kan være annerledes

\section{Tall fra levekårsundersøkelsen blant innvandrere viste at dobbelt så mange innvandrere rapporterte om psykiske plager sammenliknet med den ovrige befolkningen}

blant innvandrere sammenlignet med etniske nordmenn. Selvmordsatferd blant innvandrere kan påvirkes negativt av selve migrasjonsbelastningen. På den annen side kan kulturelle faktorer og lavere selvmordsrisiko i opprinnelseslandene være faktorer som beskytter mot selvmord.

En nylig publisert oversiktsartikkel som undersøker alle studier på engelsk fra 1980 til 2017 som sammenligner selvmordsrisiko blant innvandrere og etniske minoriteter med innfødt majoritetsbefolkning, viste varierende resultater (Forte et al., 2018). De fant at en del av studiene rapporterte lavere selvmord og selvmordsforsøk blant innvandrerne/minoritetene. Andre studier fant høyere rater, og andre igien fant ingen signifikant forskjell. Totalt sett konkluderte forsk- 


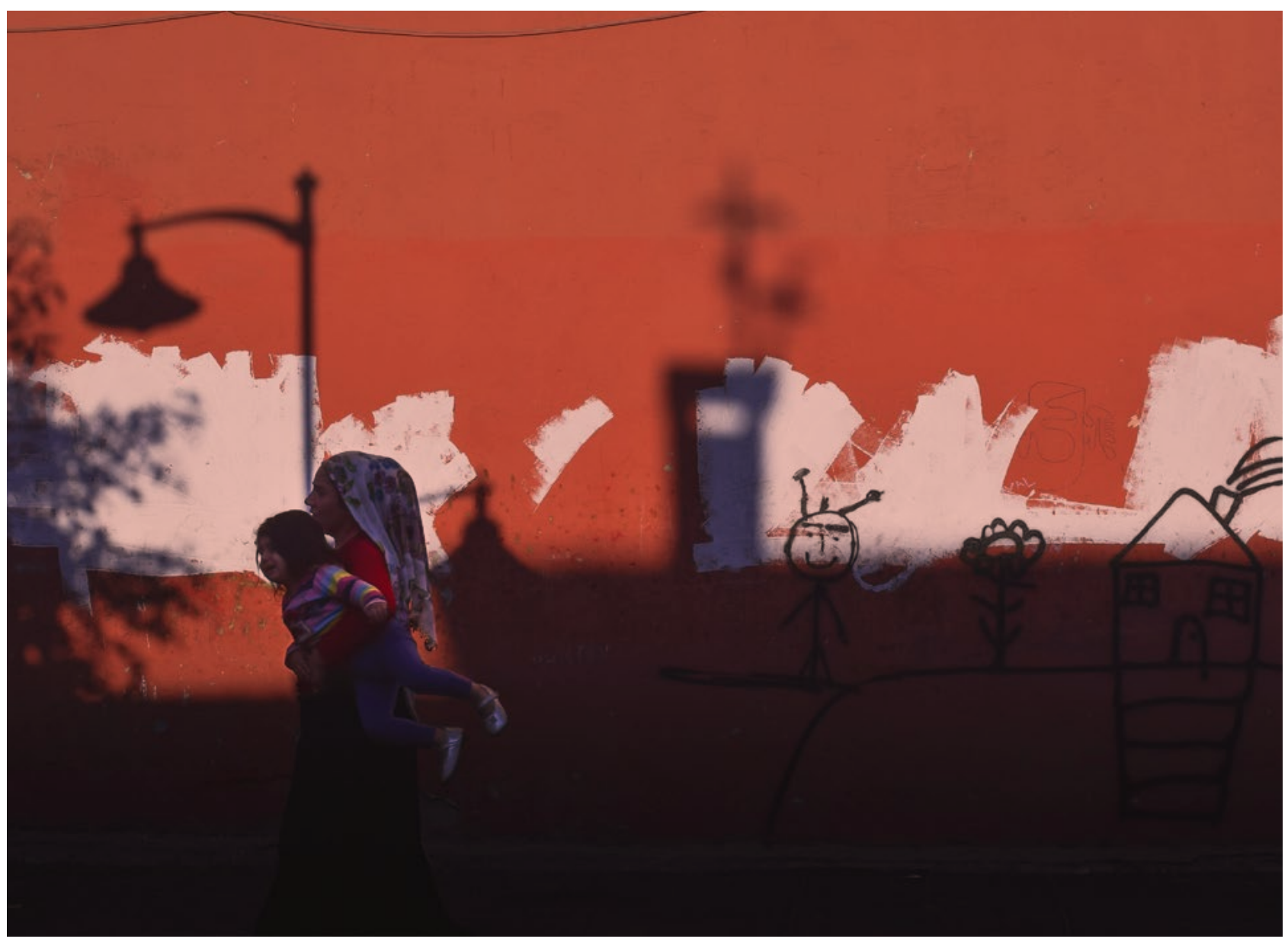

erne med en positiv korrelasjon mellom selvmordsatferd og bestemte opprinnelsesland.

Forekomst av selvmord og alvorlige selvmordshandlinger har vært studert i mange tiår både i Europa og Nord-Amerika. I USA er tallene klart høyere enn i de fleste europeiske land. Amerikanske myndigheter har heller ikke klart å få redusert forekomsten på samme måte som i Europa (WHO, 2014). En kan derfor spørre seg om selvmordsraten blant innvandrere i Europa er annerledes enn blant innvandrere i Amerika, og det er mye som tyder på det.

I Storbritannia finner man for eksempel høyest selvmordsforekomst blant yngre innvandrermenn av øst-europeisk og karibisk opprinnelse og flest selvmordsforsøk blant ikke-europeiske innvandrerkvinner (fra Afrika, Karibiske øyer, Sør-Asia og Kina) (Shah et al., 2011; Bhui \& McKenzie, 2008). I disse studiene var det å være født i Vest-Europa beskyttende, også for innvandrerne.

En del studier fra USA viser den motsatte trenden (Borges et al., 2012; Quinlan-Davidson et al., 2014; Blum et al., 2012). Det er generelt lavere selvmordsrisiko blant innvandrere sammenlignet med ovrig befolkning i USA. For eksempel har unge voksne fra latinamerikanske land som Cuba, Mexico og Puerto Rico vesentlig lavere selvmordsrater enn alderssammenlignet øvrig amerikansk befolkning (Quinlan-Davidson et al., 2014). Forekomst av selvmordstanker og -forsøk var også betydelig lavere i Vietnam og Kina, og førstegenerasionsinnvandrere derfra, sammenlignet med USAs befolkning (Blum et al., 2012).

Det er også stor variasjon i selvmordsratene europeiske land imellom. For eksempel er det nesten ti ganger høyere selvmordsrate i Russland enn i Hellas. Generelt sett er det lavest selvmordsrate i Sør-Europa og høyest i Nord- og Øst-Europa (Varnik, 2012; Spallek et al., 2015). Man kan tenke seg at innvandrere fra land med høy selvmordsrisiko tar med seg noe av dette ved migrasion til et land med lavere risiko, og vice versa (Spallek et al., 2015; Voracek \& Loibl, 2008). Selvmordsrisikoen blant innvandrere i alle land har en tendens til å bli mer lik den lokale befolkningen med økende oppholdstid. Dette skjer spesielt ved påfølgende generasjoner (Kliewer, 1991).

Innad i Norden er det også variasjon. Forekomsten av selvmord er nokså lik i Danmark, Norge og Sverige med henholdsvis ca. 9, 10 og 11 selvmord per 100 oo० innbyggere per år. I Finland er forekomsten nesten det dobbelte av dette, og Grønland har høyest forekomst i 


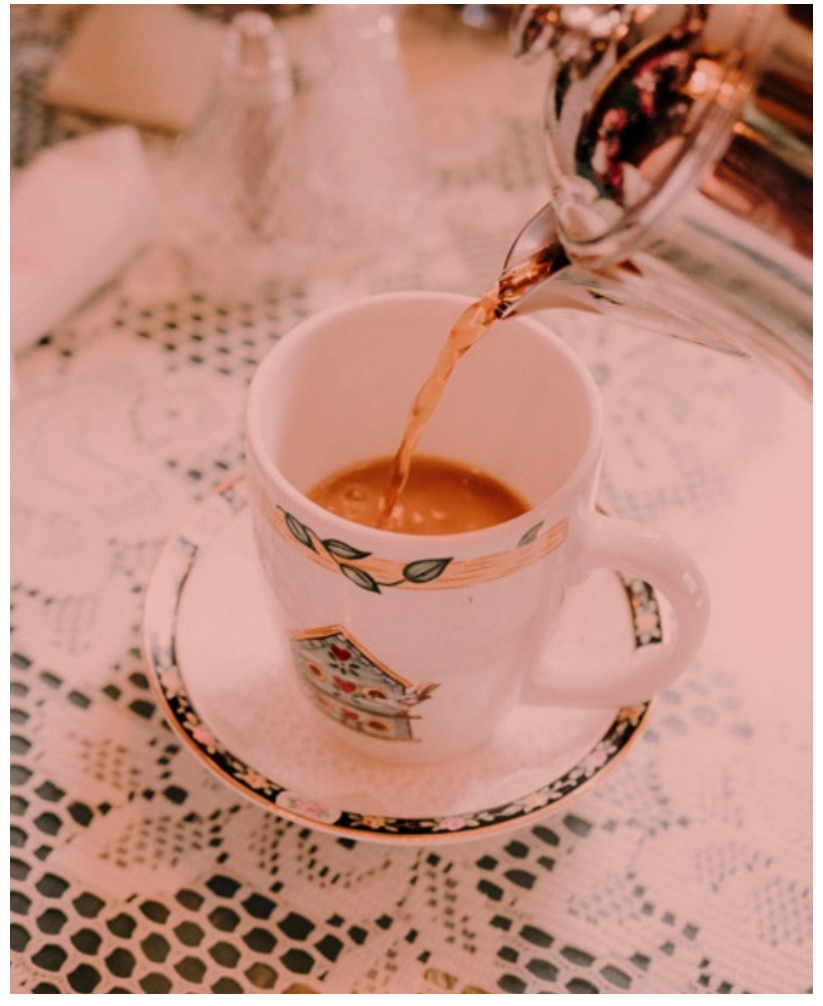

verden med ca. 83 selvmord per 100.000 innbyggere per år (Folkehelseinstituttet, 2011). Selv mellom fylker i Norge er det relativt stor forskjell, der for eksempel Hedmark har hatt omtrent dobbelt så høy forekomst av selvmord som Akershus giennom flere tiår (Statistisk sentralbyrå, 2018).

Dermed er det mye som tyder på at kultur og subkultur spiller en viktigere rolle enn geografi. Selvmordstallene i Norge har vært relativt stabile med 500-600 registrerte selvmord per år, til tross for at myndighetene har hatt fokus på å redusere dette (Folkehelseinstituttet, 2011). En nylig publisert studie av befolkningsregistre i Norge viser at første- og andregenerasjonsinnvandrer i Norge har en lavere risiko for selvmord enn etnisk norske nordmenn. Imidlertid var risikoen for personer med blandet norsk- og innvandrerbakgrunn betydelig høyere enn hos etnisk norske. Det ble observert signifikant variasion i suicidal atferd etter opprinnelsesland. Innvandrere fra Øst-Europa, Asia og Afrika begikk selvmord etter færre år med opphold i Norge enn innvandrere fra vestlige land (Puzo et al., 2017). Selvmord blant innvandrere hadde også en sterkere assosiasjon med sosioøkonomisk status enn blant etniske nordmenn (Puzo et al., 2018). Annen forskning har også vist at innvandrere kan ha særskilte risikofaktorer for selvmord som språkbarrierer, bekymring for familie langt unna, mangel på informasjon om samfunnet og helsevesenet, tap av status, tap av sosialt nettverk og akkultureringsstress (Wyatt et al., 2015),

I vår kliniske hverdag møter vi mange pasienter med utenlandsk bakgrunn. Mange preges av et høyt lidelsestrykk, blant annet med mye somatisering og kroniske smerter. Innvandrere rapporterer ofte mer maktesløshet, flere negative livshendelser, lavere inntekt og færre er i lønnet arbeid. Når det gielder selvmordsrisikoen hos slike pasienter blir den imidlertid oftere vurdert som lav. En av forklaringene kan være at innvandrere kan ha sterkere familiære nettverk, kulturelle tradisjoner og religion som virker beskyttende mot selvmord. De har oftere barn og det kan være en sterk motivasjon for å ikke ta sitt liv. Mange pasienter ved vårt DPS i Søndre Oslo har religiøs tro som forbyr selvmord. I tillegg har de mindre forbruk av alkohol og andre rusmidler som er kiente sterke risikofaktorer for selvmord. Vi har også erfart at noen innvandrere er mer vant med å takle motgang og håndtere livspåkjenninger. Dette kan være ferdigheter de har med seg fra barndommen.

Det viktigste blir å huske at innvandrerbefolkningen ikke er én gruppe. Hvert individ, har sine risikofaktorer og beskyttende faktorer for selvmord, inkludert etnisitet. Selvmordsrisiko endrer seg dessuten med oppholdstiden og er preget av individuelle erfaringer før, under og etter migrasjon. Kulturell bakgrunn, familiesituasion, religion, tilhørighet, livshendelser, migrasjonsgrunn, integreringsgrad og sosial støtte og andre psykososiale forhold spiller viktige roller i denne prosessen. Man bør ta hensyn til dette ved psykiske lidelser og ved vurdering av selvmordsfare.

\section{REFERANSER}

Bhui, K. S. \& McKenzie, K. (2008) Rates and risk factors by ethnic group for suicides within a year of contact with mental health services in England and Wales. Psychiatr Serv. 2008;59(4):414-20.

Blom, S. (2010). Sosiale forskjeller i innvandreres helse: funn fra undersøkelsen Levekår blant innvandrere 2005/2006.

Blum, R., Sudhinaraset, M., \& Emerson, M. R. (2012). Youth at risk: suicidal thoughts and attempts in Vietnam, China, and Taiwan. I Adolesc Health. 2012;50(3 Suppl):S37-44.

Borges, G., Orozco, R., Rafful, C., Miller, E., \& Breslau, I. (2012). Suicidality, ethnicity and immigration in the USA. Psychol Med. 2012;42(6):1175-84.

Elstad, I., Finnvold, I., Texmon, I., \& Norsk institutt for forskning om oppvekst, velferd og aldring. (2015). Bruk av sykehus og spesialisthelsetienester blant innbyggere med norsk og utenlandsk bakgrunn (Vol. 10/2015, NOVArapport (trykt utg.)). Oslo: Norsk institutt for forskning om oppvekst, velferd og aldring.

Folkehelseinstituttet. (2011). Fakta om selvmord og selvmordsforsøk Oslo, Norway2011 [updated 12.12.2017; cited 2017 12.12].

Forte, A., Trobia, F., Gualtieri, F., Lamis, D. A., Cardamone, G., \& Giallonardo, V. (2018). Suicide Risk among Immigrants and Ethnic Minorities: A Literature Overview. Int I Environ Res Public Health. 2018;15(7)

Guribye, E. (2011), «No God and no Norway»: collective resource loss among members of Tamil NGO's in Norway during and after the last phase of the civil war in Sri Lanka. International journal of mental health systems. 2011;5:18. 
Hjorthoi, C. R., Madsen, T., Agerbo, E., \& Nordentoft, M. (2014). Risk of suicide according to level of psychiatric treatment: a nationwide nested case-control study. Social psychiatry and psychiatric epidemiology. 2014;49(9):1357-65.

Kliewer, E. (1991). Immigrant suicide in Australia, Canada, England and Wales, and the United States. Journal of the Australian Population Association. 1991;8(2):111-28.

Lee, I. I. H., Helke, I. \& Laczko, F. (2015). World Migration Report 2015 Migrants and Cities: New Partnerships to Manage Mobility (World Migration Report). International Organization for Migration. Hentet fra http://publications.iom.int/system/files/wmr2015_en.pdf .

Lindert I., Ehrenstein, O. S., Priebe, S., Mielck, A., \& Brahler, E. (2009). Depression and anxiety in labor migrants and refugees--a systematic review and meta-analysis. Social science \& medicine (1982). 2009;69(2):246-57.

Norredam, M., Olsbierg, M., Petersen, I. H., Laursen, B., \& Krasnik, A. (2013). Are there differences in injury mortality among refugees and immigrants compared with native-born? Injury prevention : journal of the International Society for Child and Adolescent Injury Prevention. 2013;19(2):100-5

Puzo, Q., Mehlum, L. \& Qin, P. (2017). Suicide among immigrant population in Norway: a national register-based study. Acta psychiatrica Scandinavica. 2017:135(6):584-92

Puzo, Q., Mehlum, L. \& Qin, P. (2018). Socio-economic status and risk for suicide by immigration background in Norway: A register-based national study. Journal of psychiatric research. 2018;100:99-106.
Quinlan-Davidson, M., Sanhueza, A., Espinosa, I., Escamilla-Cejudo, I. A., \& Maddaleno, M. (2014). Suicide among young people in the Americas. I Adolesc Health. 2014;54(3):262-8.

Shah, A., Lindesay, I. \& Dennis, M. (2011). Suicides by country of birth groupings in England and Wales: age-associated trends and standardised mortality ratios. Soc Psychiatry Psychiatr Epidemiol. 2011;46(3):197-206.

Spallek, I., Reeske, A., Norredam, M., Nielsen, S. S., Lehnhardt, I. \& Razum, O. (2015). Suicide among immigrants in Europe--a systematic literature review. European journal of public health. 2015;25(1):63-71.

Statistisk Sentralbyrå. (2018a) Dødsfall ved selvmord 2015 [cited 2018 19.03.19]. Available from: https://www.ssb.no/a/histstat/tabeller/4-14.html.

Statistisk sentralbyrå. (2018b) Fakta om innvandring Oslo, Norway: Statistisk sentral byrå; 2018 [cited 2018 18.10]. Hentet fra https://www.ssb. no/innvandring-og-innvandrere/faktaside/innvandring.

Varnik, P. (2012). Suicide in the world. International journal of environmen tal research and public health. 2012;9(3):760-71.

Voracek, M. \& Loibl, L. M. (2008). Consistency of immigrant and countryof-birth suicide rates: a meta-analysis. Acta psychiatrica Scandinavica. 2008;118(4):259-71.

WHO. (2014). Preventing suicide. A global imperative. Geneva, Switzerland: United Nations; 2014.

Wyatt, L. C., Ung, T., Park, R., Kwon, S. C., \& Trinh-Shevrin, C. (2015). Risk Factors of Suicide and Depression among Asian American, Native Hawaiian, and Pacific Islander Youth: A Systematic Literature Review. I Health Care Poor Underserved. 2015;26(2 Suppl):191-237.

\section{Utdanning i DBT}

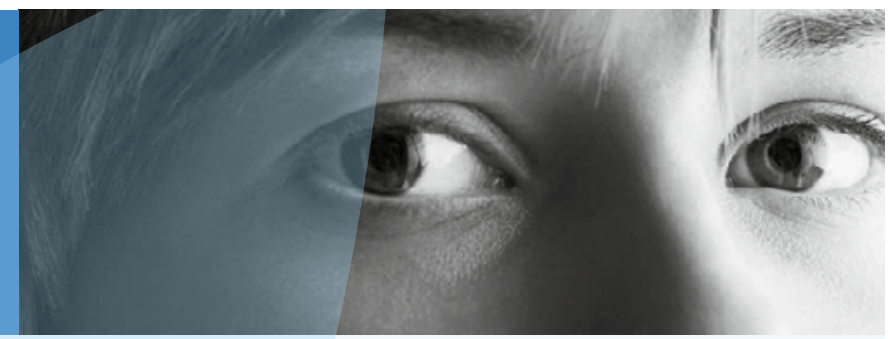

Dialektisk atferdsterapi (DBT) er anbefalt som behandlingsmetodikk overfor pasienter med selvskading, selvmordsforsøk og ustabil personlighetsforstyrrelse.

Neste kull starter i Oslo, januar 2020

Søknadsfrist 1. november 2019

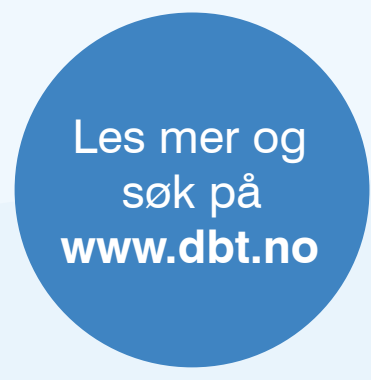

